\title{
Understanding Writing Difficulties through a Model of the Cognitive Processes Involved in Writing
}

\author{
Lynsey O'Rourke, Vincent Connelly and Anna Barnett*
}

The cognitive tradition of writing research has produced a number of models of the processes involved in producing written text. The models and frameworks have mainly been derived from work on competent adult writers, although there are a growing number of investigations of the writing development of younger children. (For example, until recently $80 \%$ of peer reviewed studies on writing were on adults; Juzwik et al., 2006). These many models rely on traditional cognitive research methods to determine the processes involved with writing.

Children with "specific learning disorder" in DSM-5 include those with difficulties in learning, reading, maths, and written expression, defined by a lack of progress in the requisite academic skills; these skills must fall well below the average and not be explainable by other neurological, developmental and sensory disorders (American Psychiatric Association, 2013). Disorders of written expression in particular as a sub-set of specific learning disorders are identified by problems with spelling accuracy, grammar and punctuation, poor and slow handwriting, and a lack of clarity and organisation of written expression. These problems with written expression co-occur with other learning disorder categories in common use, such as dyslexia and Language Learning Difficulty (LLD) (See Connelly, Dockrell, \& Barnett, 2011). Therefore, it is to be expected that writing difficulties will be associated with a range of developmental problems (Dockrell, 2009).

In this chapter, we consider these developmental problems in the light of a recent cognitive model of the development of writing processes (Hayes \& Berninger, 2014), to illustrate how such models can be useful when thinking about the difficulties children with specific learning disorders encounter when learning to write. We also remark on the ambiguities and gaps in knowledge in

\footnotetext{
* This paper was supported in part by a doctoral grant to the first author from Oxford Brookes University. Correspondence concerning this chapter should be addressed to Vincent Connelly.
}

(C) KONINKLIJKE BRILL NV, LEIDEN, 2018 | DOI: 10.1163/9789004346369_003

This is an open access chapter distributed under the terms of the prevailing CC-BY-NC License at the time of publication. 
these cognitive models and the consequent issues that need to be considered when working with some of the special populations of children who struggle with writing.

Of course, there are many other cognitive models of writing and we are not stating that the model we discuss is more worthy than other models published; we do not have space to include details of others and so concentrate on the one model in detail as an example. Other popular cognitive models of writing, such as the Bereiter and Scardamalia (1987) model, have many commonalities with the model we discuss as well as having some significant differences in how they explain change in writing behaviours (See MacArthur \& Graham, 2016). There are also alternative non-cognitive models of writing and while these are also beyond the scope of this chapter, we do recognize the usefulness of these alternate, usually socio-cultural, models and the possibility of integrating such research with the work described here to produce a broader understanding of writing (for further exhortations along these lines, see Boscolo, 2014).

\section{Hayes \& Berninger (2014) Cognitive Processes in Writing Framework}

Hayes and Berninger's recent model (or as they term-framework) on cognitive processes in writing was specifically designed to be adapted to work with individuals who have writing difficulties (Hayes \& Berninger, 2014). This work is an update and amalgam of much previous work on the development of writing processes with the origins going back over thirty years (Flower \& Hayes, 1980); this ongoing work has been steadily modified and updated by more recent research evidence (e.g., Chenoweth \& Hayes, 2003). The current framework is based around a skilled typically developing writer but is also informed by work on children with writing difficulties (Berninger \& Amtmann, 2003).

In this framework (See Figure 2.1) Hayes and Berninger postulate that a typical writer will develop writing though the development and integration of three "levels" for producing writing: resource, process, and control levels. Successful writing demands the interactions of these levels and simultaneous processing, when possible, across levels to both speed up the writing process and to ensure that no relevant ideas are lost due to cognitive bottlenecks or dysfluent processes before they can be written down (Olive, 2014). The process of writing therefore involves increasing integration of these levels where, for the most skilled writers, the product is actually greater than the simple sum of its parts (Connelly \& Dockrell, 2016). 


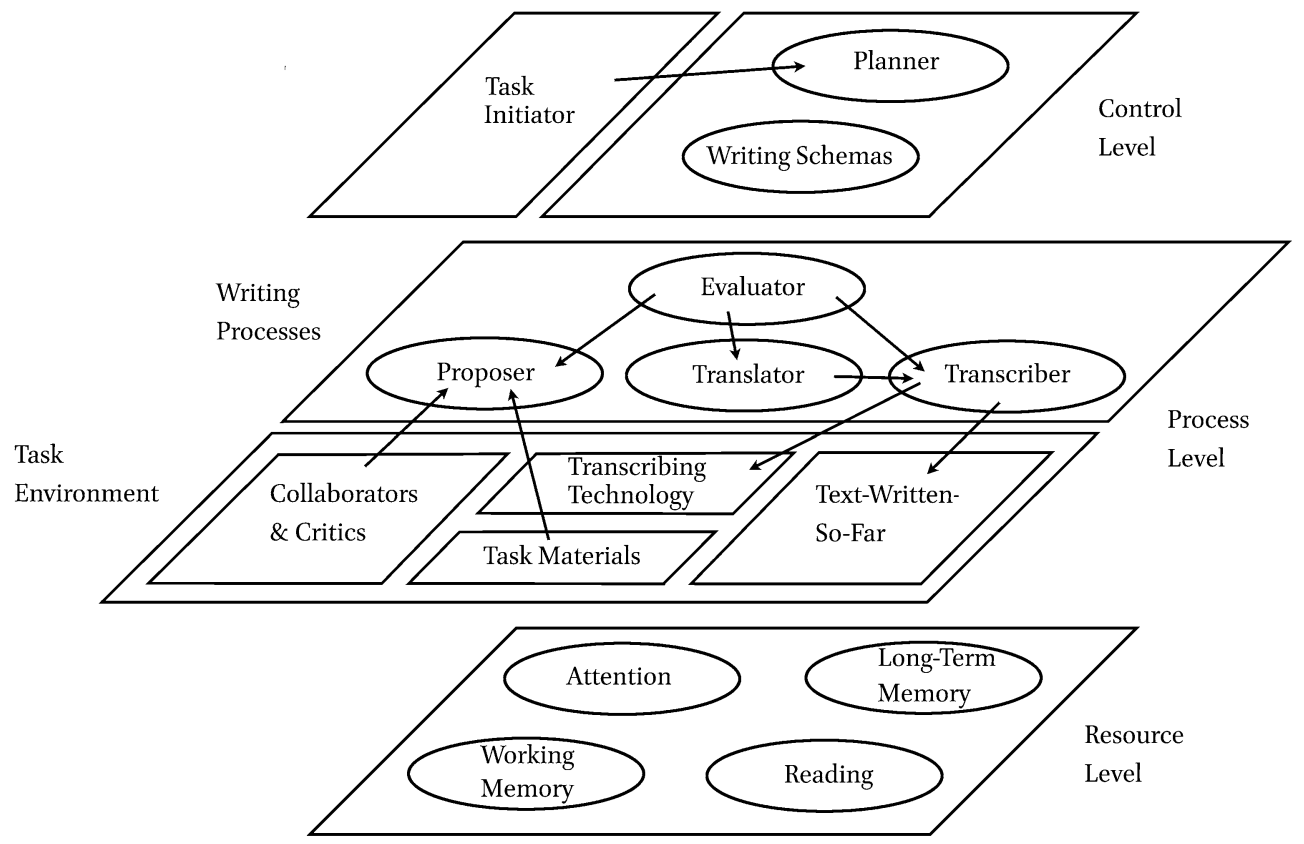

FIGURE 2.1 The Hayes \& Berninger (2014) framework representing the organization of cognitive processes involved in writing BY PERMISSION OF OXFORD UNIVERSITY PRESS, USA (WWW.OUP.COM)

However, prior to full integration, writing will tend to be slow and be constrained by the levels that demand the most processing power. Many of the cognitive processes mapped out within the three levels draw upon common cognitive processes used in many everyday activities such as memory, speaking, listening, and reading. Thus, those individuals with specific learning difficulties in these areas will struggle to develop their writing processes from the very beginning of learning to write. There are some suggestions from Hayes and Berninger about how those children with writing difficulties can be more clearly understood. For example, children who are deaf have difficulties in developing their working memory, which impacts on word and sentence level aspects of writing (Arfé, Nicolini, \& Pozzebon, 2014) and children who find it difficult to grasp inference in speech may have difficulty with the proposing of ideas, leading to poorer quality written texts (Hayes \& Berninger, 2014). Our goal in this chapter is to take the various parts of the framework and link them to recent evidence about children who struggle to learn to write (especially those two most common learning disorders often referred to as dyslexia and LLD) and to illustrate where there are debates about our gaps in knowledge in terms of the framework for future research. 


\section{The Resource Level}

The resource level draws on four cognitive areas required for writing that can be slow to develop in children with specific learning difficulties: attention, long term memory, working memory, and reading. Attention in this framework is a variant of what is also termed executive function elsewhere, a resource that the control level can draw upon when writing. Long-term memory is broadly defined in this framework and includes not just memory of facts and events but also memory for motor planning, motor control, and motor execution skills (including letter form knowledge) as well as the large domain of language.

The model is not yet precise in how these different resources interact with the development of writing. For example, the clustering of language and motor skills within the resource of long-term memory may require some fractionating. It has recently been shown that motor planning for letter forms by 8 year olds can be influenced by the text written so far (Pontart et al., 2013). Recent work on children with Developmental Co-ordination Disorder (DCD) has shown that these children can have typical language skills but difficulties with writing that reflect a motor problem (Prunty, Barnett, Wilmut, \& Plumb, 2014). In a recent review of writing research, Olive (2014) argues there is clear evidence that motor processes are separate from central conceptual and linguistic processes. Thus, in order to understand how children with language or motor difficulties struggle with writing, it may be useful to consider motor and language areas as separate resource areas to be drawn upon whose contributions can be perhaps individually measured against writing.

Language clearly demands a central place in any framework for the cognitive processes in writing. Yet, it is not clear why language is not more visibly highlighted in the framework and is instead considered to be part of long-term memory. There is much evidence showing that oral language is key to supporting the development of written language (McCutchen, Stull, Herrera, Lotas, \& Evans, 2014; Mehta, Foorman, Branum-Martin, \& Taylor, 2005; Wagner et al., 2011). There is also growing understanding of (1) the ways in which children with LLD who struggle with oral language also struggle with writing (Dockrell, \& Connelly 2009; Dockrell, Lindsay, Connelly \& Mackie, 2007), (2) that one of the key impacts of LLD on writing is through poor vocabulary (Dockrell, Lindsay, \& Connelly, 2009), and (3) that these vocabulary difficulties can have different impacts on writing than do difficulties in other language areas such as grammar (Dockrell \& Connelly, 2015, 2016). In addition, this differs across languages: other research on language and writing has shown that different languages make their own specific demands on the development of spelling and grammar (Kandel, Hérault, Grosjacques, Lambert, \& Fayol, 20o9). Lan- 
guages with more transparent orthographies may present more grammatical challenges earlier on to those struggling with writing (Arfé, Dockrell, \& De Bernardi, 2016) than do those languages with deeper orthographies that may be typified by more problems with spelling and handwriting (Dockrell, Lindsay, \& Connelly, 2009).

Reading is also a key area of cognition related closely to writing (Shanahan, 2006). Children with reading difficulties tend to have problems with the phonological aspects of language that impair the development of both reading and spelling. Poor word recognition and poor spelling will have long term impacts on reading comprehension, depth of vocabulary, and familiarity with grammatical structures. Rapid fluent reading when reviewing a text eases cognitive load on working memory and allows quick access to long term memory and subject-specific knowledge. For example, reading and re-reading text written so far is common in typical readers and writers, and rereading is associated with increased text quality (Wengelin, Leijten, \& Van Waes, 2010). Some other work has also shown that amount of re-reading in adolescents is associated with more sophisticated sentence-level planning and text production schemas (Beers, Quinlan, \& Harbaugh, 2010) and that there is a strong relationship between reading, cognitive load, and spelling error detection within the text written so far (Van Waes, Leijten and Quinlan, 2010). Therefore, individuals with reading difficulties will likely be slower at reading the text written so far, poorer at spotting written errors such as spelling mistakes, and more limited in their engagement with that text.

A substantial body of knowledge has also shown that working memory is a particular difficulty for the majority of children with specific learning difficulties. There is much research investigating how working memory resources can constrain writing since the production of writing demands that many different cognitive processes be simultaneously activated to produce text (Flower \& Hayes, 1980). There are debates in the literature as to whether working memory is a general resource that provides an overall general capacity and can be accessed as required by any combination of resource-demanding processes involved in writing or whether working memory capacity is fractionated into smaller resource pools related to specific processes (Fayol, 1999; McCutchen, 2011; Torrance \& Galbraith, 2006). Kellogg, Whiteford, Turner, Cahill, \& Merlens (2013) endorse the classical view of working memory as it relates to writing and view it as possessing a central executive with slaved storage systems, such as the phonological loop and visuo-spatial sketch pad (Baddeley, 2007) allied to verbal, visual, and spatial short term memory systems. Kellogg and colleagues (Kellogg et al., 2013) have applied this model to writing and reviewed the evidence for the components of working memory in writing. For example, 
they present evidence for a central executive role in most critical writing functions (such as planning, translating, and reviewing) and posit that the central executive functions of updating representations in working memory, switching between tasks, and inhibiting responses are all important to writers.

Interestingly, overall working memory capacity has been found to be only weakly related to text quality in some studies of younger primary school children (Swanson \& Berninger, 1996a), but is more strongly related in teenage children (Swanson \& Berninger, 1996b). However, at most ages children and adults writing in specific areas such as sentence construction or word spelling show disruption when loading specific aspects of working memory such as the phonological loop (Kellogg, Olive, \& Piolat, 2007). This supports the idea that parts of the working memory system support specific aspects of writing. For example, Kellogg and colleagues (2013) review research demonstrating processing and storage roles for the phonological loop to support verbal working memory while translating ideas into appropriate written language and indicating that this has a major impact on word and sentence processing (e.g., Chenoweth \& Hayes, 2003). Further, there may be evidence to support a role for an orthographic loop in the production of accurate spelling (Richards, Berninger, \& Fayol, 2009). There also continues to be debate about the potential role of the visuo-spatial sketchpad and visual memory for planning functions in writing, with more convincing evidence for advanced writers but less for younger writers (Galbraith, Ford, Walker, \& Ford, 2005; Olive, Kellogg, \& Piolat, 2008). Rather than conclude that children should benefit from training to improve working memory (for which there is little effective classroom evidence, e.g., Dunning, Holmes, \& Gathercole, 2013), Kellogg and colleagues (2013) point to strategies to reduce working memory load on writers. For example, tapping into expert topic knowledge enables writers to bypass working memory and directly access long term memory (McCutchen, 2011). Alternatively, the load on the central executive may be reduced by teaching writing strategies that allow the writer to serially implement writing processes in the classroom (See Graham \& Perin, 2007). There is also evidence that working memory load is reduced through direct access to related cognitive abilities in language (e.g., research showing that girls' superior language skills allow them to make faster progression in writing than boys; Bourke \& Adams, 2011).

Kellogg and colleagues (2013) also encourage explicit repetitive practice for writers in specific skills such as spelling, handwriting, or sentence combining to automatise writing processes and demand fewer resources within working memory. While the mechanisms by which repetitive practice allows skills to become more automatic are still being debated, there is abundant evidence through secondary task experiments that repetitive practice does reduce cog- 
nitive load; there is also abundant evidence of effective intervention in skills through repeated practice (Graham \& Perin, 2007). The important aspect of a reduction of cognitive load is that it would appear to allow a writer to begin to process writing functions in parallel through supporting the integration of those functions at the resource and the process level (Olive, 2014).

\section{The Process Level}

The process level (see Figure 2.1 for relative hierarchy of the levels) includes the specific writing processes used to create text; it is based on the previously published Chenoweth \& Hayes (2003) model of text generation. Thus, the process level includes the proposer, translator, and transcriber processes interacting with an evaluator process alongside an interactive component; that interactive component takes into account the various factors important to monitor and respond to in the task environment (i.e., the task materials, text written so far, transcribing technology and any "collaborators and critics"). There is much published work on the different aspects of text generation specified in the model, since it represents the conceptually oldest piece of the framework to be proposed (Flower \& Hayes, 1980).

\section{Developing Text Generation}

Translating ideas to text depends on the development of the text generation aspect of the framework. The key processes to be developed are transcription and translation, with a more slowly developing evaluator function. Relatedly, the proposer is assumed to be a function derived directly from language. Thus, transcription is thought to be the first process to constrain writing in the primary grades (up to $5^{\text {th }}$ grade, ages $6-10$ ). It depends on the coordination of linguistic abilities, orthographic knowledge, fine motor skill, and the degree to which coordination of all three occurs automatically. When this coordination reaches a certain point, then cognitive resources are freed up; as writers move to intermediate grades (ages 11-14), translation skills develop, and together with more automated transcription, "text generation can steadily graduate from single words to grammatical clauses, then to paragraphs combining several sentences" (p. 27, Alamargot \& Fayol, 2009). There then follows a period when translation slowly matures; thus, a lack of translation maturity becomes the constraining factor in intermediate grade level writing. Again, through instruction and practice, translation develops to a point where cognitive resources are available to support advanced composition and structuring text, usually when children are progressing into the later grades (Berninger \& Swanson, 1994). 
It is generally accepted that as writers develop their writing processes, over time and given adequate practice, these processes require less effort and use fewer cognitive resources. Olive (2014) describes how skilled writers may coordinate levels of processing, such as transcription and translation, so that they can be run concurrently in a cascading system. This process is then coordinated by the central executive. This cascade allows a continuous flow of information from process to process, without requiring processes to run to completion. Furthermore, the ability for processes to cascade and run in parallel depends on the size of demand, working memory capacity, and whether resources are indeed transferable. Thus, younger children and those older children with writing difficulties often find it difficult to implement parallel processing and tend to rely more on serial processing (Olive \& Kellogg, 20O2). Individual differences in resource areas such as language, working memory, and reading impact on the ability to parallel process information by creating information bottlenecks at points in the text generation process.

Research with adults has demonstrated that bottlenecks in processing can occur between different areas during text generation. For example, Roux and Bonin (2012) asked participants to write the names of pictures superimposed with either other congruent or interfering pictures. Semantic information from interfering pictures was shown to reduce the fluency of written production, demonstrating a bottleneck in processing between translation and transcription functions during lexical selection. Other data on adults has demonstrated that processing bottlenecks between the proposer and translator modules were directly linked to differing language abilities in adults (Chenoweth \& Hayes, 2003). This has been confirmed in work with children with language learning difficulties (LLD) who show very impaired writing in terms of quality of ideas and language, especially related to grammatical complexity, compared to their same age peers (Dockrell \& Connelly, 2015, 2016; Puranik, Lombardino, \& Altmann, 2007); these impairments were predicted by the students' language difficulties.

Other children, such as those who have problems with spelling when transcribing (e.g., those with dyslexia or LLD) have processing bottlenecks around transcription. We know these children do not have difficulty with the translator, as they can dictate essays to the same standard as peers. However, the quality of their written essays is worse than peers and is predicted by spelling ability (Sumner, Connelly, \& Barnett, 2014a); they often exhibit long pauses around the spelling of difficult words, and they display a hesitant writing style that is related to poorer compositional quality (Sumner, Connelly, \& Barnett, 2013). Such students generally take a long time to produce short texts with poorer written vocabulary than their same age peers. The poorer written vocabulary is 
due to the selection of words for transcription that are simple to spell but that are not necessarily the most appropriate for the written context, and thus is predicted by the spelling capability of the children (Sumner, Connelly, \& Barnett, 2016). This is evidence of the translator process having to deal with the consequences of a transcription difficulty. The slowness of text generation by these children is thus also a product of the evaluator, transcriber, and translator having to select, deselect, and reselect written vocabulary throughout text generation. Thus, children with spelling difficulties generally exhibit long pauses between words as well as within words when producing written text (Sumner, Connelly, \& Barnett, 2013).

Children with spelling difficulties remain slow, hesitant writers well into adulthood, even when the spelling is provided for them in a copy task (Afonso, Suarez-Coalla, \& Cuetos, 2015; Connelly, Dockrell, Walter, \& Critten, 2012; Sumner, Connelly, \& Barnett, 2014a, 2016). However, adults with spelling difficulties who progress into Higher Education are much more likely to be able to overcome their hesitant writing style and produce writing comparable to their peers in terms of the quality of ideas and overall content, although still retaining more errors of spelling, grammar, and punctuation (Connelly, Campbell, MacLean, \& Barnes, 2006; Sumner, Connelly, \& Barnett, In Press). Despite this progress, the poorer spelling, grammar, and punctuation of these texts still leads those assessing the texts to give them lower scores compared to text produced by their peers without such difficulties (Coleman, Gregg, McLain, \& Bellair, 2009).

While there is much evidence about the roles and interaction of the core processes of proposer, translator, transcriber, and evaluator, there is much less known about the "task environment". Obviously, the task environment can have direct consequences for those with writing difficulties. For example, information technologies are often prescribed to help those children with writing difficulties. Evidence of current writing practices in U.S. schools demonstrates that use of information technology is still uncommon for writing in primary, middle and high schools (Cutler \& Graham, 20o8; Graham, Capizzi, Harris, Hebert, \& Morphy, 2014; Gillespie, Graham, Kiuhara, \& Hebert, 2014), and that teacher-provided adaptations for struggling writers that used information technology were far behind other adaptations in frequency of use (Graham, Harris, Bartlett, Popadopoulou, \& Santoro, 2016). This is despite strong evidence that the use of technology to teach writing to struggling writers has been shown to be an effective and motivational tool for improvement (Morphy \& Graham 2012).

However, information technology can come with its own burdens that are often not taken into account when it is introduced to the classroom (Mac- 
Arthur, 2006). For example, using a keyboard efficiently requires a child to be explicitly taught keyboarding (Connelly, Gee, \& Walsh 2007); otherwise children may perform keyboarding in a less than efficient manner (Grabowski, 2008) or spend more time looking at the keyboard than at the monitor (Johansson, Wengelin, Johansson, \& Holqvist, 2010), and there is a high risk that their written outputs will be of lower quality than handwritten equivalents (Christensen, 2004; Connelly et al., 2007). Other recent research seems to show that use of keyboards for note taking encouraged simple literal transcription rather than the précis which is more usual in handwritten note taking (Mueller \& Oppenheimer, 2014). Therefore, there remains much to be researched within the task environment to understand how information technology can be used to best support struggling writers (See also Rønneberg,Johansson, Mossige, Torrance \& Uppstad, this volume).

\section{The Control Level}

Hayes and Berninger (2014), in their framework, also detail a control level that draws together a task initiator and planner with a bank of writing schemas that feed down, control, and constrain how the specific writing processes operate (see Figure 2.1). Writing schemas "represent the writer's beliefs about the properties that the text to be produced should have (genre knowledge) and also beliefs about how to go about producing that text (strategic knowledge)" (p. 9, Hayes \& Berninger, 2014). These schemas largely determine how the processes at the process level are used, and how they interact with the task environment.

The control level draws upon the attention process from the resource level (see Figure 2.1 for relative hierarchy of levels), and this allows the writer to develop a focus on a writing task in the face of distraction and to maintain motivation. Thus, the development of control processes with writing schemas allows the writer to modulate the writing processes involved in text generation with the task environment through the application of appropriate schemas while drawing upon, where necessary, the general cognitive resources level. This integration of levels and processes produces fast, cascading, and parallel functioning across the framework and so allows a system that is greater than the mere sum of parts.

There are many unanswered questions regarding the control level and how indeed processes are controlled and co-ordinated across writing (Olive, 2014). There are also questions about the extent of the role of working memory as either a domain general or domain specific function and whether executive 
functions nested within working memory are part of or overlap with the control level hypothesised by Hayes and Berninger (2014). There is evidence that, as individuals with writing difficulties progress, they can develop sufficient function across processes to allow for some cascading and parallel processing. As discussed, individuals with dyslexia in Higher Education can produce writing with ideas comparable to their peers and are as fluent at writing, but at a cost of lower levels of spelling, grammar, and punctuation (Connelly et al., 2006; Sumner et al., In Press). Thus, these individuals may be showing evidence of their mastery of control processes by allocating cognitive resources to ensure that the translation of text is appropriate and that difficulties in transcription processes are more limited in impact. Further work regarding this hypothesis will be required.

Development of appropriate writing schemas at the control level may provide a way to circumvent some of the difficulties experienced by individuals with SLD when coordinating the processes involved in fluent writing vis-à-vis Hayes and Berninger (2014). It is noticeable that the largest effect sizes in studies examining writing interventions have been seen for those studies where explicit writing schemas were learnt by children as part of the intervention (Graham \& Perin, 2007). Building on this evidence, Hayes \& Olinghouse (2015) recommend that teachers should ensure that writing schemas are a key part of the writing curriculum. Schemas to develop knowledge of genre, structures and formats, strategies for producing text, and task and audience influences should be taught so they are available for conscious use by children when writing. Children should be able to draw upon a bank of explicit and well-practiced writing schemas that they can verbalise and use in the appropriate writing situations. However, Hayes and Berninger have suggested that some advanced writing schemas are only developmentally possible once language and executive functions are well advanced (Hayes \& Berninger, 2014). Thus, there is still work to do here for children with writing difficulties, as these children often do not develop language or executive functions as quickly as other children, as reflected in the lack of progress many of these children make despite interventions and practice at writing (Dockrell et al., 2009).

\section{Conclusions}

The framework proposed by Hayes and Berninger (2014) suggests a complex and highly interactive writing system that can be influenced and developed in many different ways. The precise nature of how the different levels develop and interact is not yet specified in detail in this or, in fact, in any similar 
recent model (Olive, 2014). However, using this framework, we can surmise that children who have difficulties learning to write may need support in a number of different areas. For example, they may need to be taught explicit strategies to help develop their writing processes through the development of writing schemas (Hayes \& Olinghouse, 2015), and they may require support to more effectively use their cognitive resources to support writing. (For a meta-analysis review of successful teaching strategies, see Graham \& Perin, 2007).

The framework can also help us understand that difficulties in co-ordinating or using cognitive resources such as reading will impact on the development of writing processes such as transcribing and evaluating (See Shanahan, 2006, 2015, for more details on interactions of reading with writing, and Graham \& Hebert, 2010, for evidence about successful classroom interventions to promote both). How the control level factors interact with resource level areas such as attention in order to drive the motivation to write will also be important in understanding the poor writing of those with difficulties. It seems that the "Matthew Effect" of the poor writer getting poorer over time in comparison to peers who constantly get "richer" in writing is similar to that found in reading (Connelly \& Dockrell, 2016; Puranik \& Logan, 2012). Children who struggle with writing will not get better by themselves and may begin to avoid writing altogether, without a sense of themselves as "becoming a writer" (Connelly, 2014). Stigma around writing difficulty and labels such as "dyslexia" can have a long-term impact on individuals, spurring them to even avoid help where it is offered. One student who had successfully made the entry into Higher Education, despite writing difficulties, reported not seeking advice at the university help centre to avoid being labelled (Mortimore \& Crozier, 2006). Thus, very early intervention for children with writing difficulties should be a key aim. (See Gillespie \& Graham, 2014, for a recent meta-analysis of writing interventions for students with learning disabilities.) However, such intervention development should be guided by an appreciation of writing development as illustrated by the cognitive models of writing currently available. Simply relying on diagnostic categories (dyslexia, LLD, etc.) to inform writing remediation for children who struggle, based on the surface characteristics of these diagnoses, can provide some guidance for interventions. However, a framework such as that of Hayes \& Berninger (2014) will allow teachers to identify and understand the specific areas in the writing process that are challenging the child so that targeted remediation can be developed.

The current cognitive models of writing have been useful for identifying components of the writing process, but not so useful for understanding how these components interact and how the interactions lead to change in writing development. The cognitive model of writing proposed by Bereiter and Scar- 
damalia (1987) attempted to explain development and identified when a writer had moved from less skilled to more skilled writing, likely through a series of intermediate stages (Hayes, 2011). The advent of new and more accurate writing measurement tools, automatic text analysis, and other technological tools can perhaps now help us understand these interactions, and chart writing development more finely. It also can allow us to question current theory in ways we have not been able to achieve till now (Connelly, 2014; Dockrell, Connelly, Walter \& Critten, this volume). Over and above this, studying how children learn to write with the assistance of cognitive models of writing will highlight where children are struggling with learning to write within the larger scope of all that goes into writing development, and so further inform interventions that can help overcome writing difficulties.

\section{References}

Afonso, O., Suárez-Coalla, P., \& Cuetos, F. (2015). Spelling impairments in Spanish dyslexic adults. Frontiers in Psychology, 6: 466. doi: 10.3389/fpsyg.2015.00466

Alamargot, D., \& Fayol, M. (2009). Modelling the development of written transcription. In R. Beard, D. Myhill, M. Nystrand, \& J. Riley (Eds.), Handbook of writing development (pp. 23-47). London: Sage. doi: 10.4135/9780857021069.n3

American Psychiatric Association. (2013). Diagnostic and Statistical Manual of Mental Disorders (DSM-5) (5th Ed.). Washington, DC.

Arfé, B., Dockrell, J.E., \& De Bernardi, B. (2016). The structure of early written composition and its underpinnings in a shallow orthography. Reading and Writing, 29(3), $501-527$.

Arfé, B., Nicolini, F, \& Pozzebon, E. (2014). The influence of verbal working memory on writing skills in children with hearing loss. In B. Arfé, J.E. Dockrell, \& V.W. Berninger (Eds.), Writing development and instruction in children with hearing, speech, and oral language difficulties (pp. 85-100). Oxford: Oxford University Press.

Baddeley, A.D. (2007). Working memory, thought and action. Oxford: Oxford University Press.

Beers, S.F., Quinlan, T., \& Harbaugh, G. (2010). Adolescent students' reading during writing and relationships with text quality. Reading and Writing, 23, 743-775.

Bereiter, C. \& Scardamalia, M. (1987) The psychology of written composition. Hillsdale, NJ: Lawrence Erlbaum Associates.

Berninger, V.W., \& Amtmann, D. (2003). Preventing written expression disabilities through early and continuing assessment and intervention for handwriting and/or spelling problems: Research into practice. In H.L. Swanson, K. Harris, \& S. Graham (Eds.), Handbook of learning disabilities (pp. 345-363). New York: Guilford Press. 
Berninger, V.W., \& Swanson, H.L. (1994). Modifying Hayes and Flower's model of skilled writing to explain beginning and developing writing. In E.C. Butterfield \& J. Carlson (Eds.), Children's writing: Toward a process theory of the development of skilled writing (pp. 57-81). London: JAI Press.

Boscolo, P. (2014). Two metaphors for writing research and their implications for writing instruction. In B. Arfé, J.E. Dockrell, \& V.W. Berninger (Eds.), Writing development and instruction in children with hearing, speech, and oral language difficulties (pp. 3345). Oxford: Oxford University Press.

Bourke, L., \& Adams, A.M. (2011). Is it differences in language skills and working memory that account for girls being better at writing than boys? Journal of Writing Research, 3(3), 249-277.

Chenoweth, N.A., \& Hayes, J.R. (2003). The inner voice in writing. Written Communication, 20(1), 99-118.

Christensen, C.A. (2004). Relationship between orthographic-motor integration and computer use for the production of creative and well-structured written text. British Journal of Educational Psychology, 74(4), 551-564. doi:10.1348/ooo7099042376373

Coleman, C., Gregg, N., McLain, L., \& Bellair, L.W. (2009). A comparison of spelling performance across young adults with and without dyslexia. Assessment for Effective Intervention, 34, 94-105.

Connelly, V. (2014). Integrating writing and oral language disorders: Perspectives of a writing researcher. In B. Arfé, J.E. Dockrell, \& V.W. Berninger (Eds.), Writing development and instruction in children with hearing, speech, and oral language difficulties (pp. 313-324). Oxford: Oxford University Press.

Connelly, V., \& Dockrell, J.E. (2016). Writing development and instruction for students with learning disabilities: Using diagnostic categories to study writing difficulties. In C. MacArthur, S. Graham, \& J. Fitzgerald (Eds.), Handbook of writing research, 2nd Edition (pp. 349-363). New York: Guilford Publications.

Connelly, V., Dockrell, J.E., Barnett, A. (2011). Children challenged by writing due to language and motor difficulties. In V. Berninger (Ed.) Cognitive psychology of writing handbook: Past, present, and future contributions of cognitive writing (pp. 217-246). NY: Psychology Press.

Connelly, V., Campbell, S., MacLean, M., \& Barnes, J. (2006). Contribution of lower order skills to the written composition of college students with and without dyslexia. Developmental Neuropsychology, 29(1), 175-196.

Connelly, V., Dockrell, J.E., Walter, K., \& Critten, S. (2012). Predicting the quality of composition and written language bursts from oral language, spelling and handwriting skills in children with and without SLI. Written Communication, 29, 278-302.

Connelly, V., Gee, D., \& Walsh, E. (2007). A comparison of keyboarded and handwritten compositions and the relationship with transcription speed. British Journal of Educational Psychology, 77(2), 479-492. doi:10.1348/000709906X116768 
Cutler, L., \& Graham, S. (2008). Primary grade writing instruction: A national survey. Journal of educational Psychology, 100(4), 907.

Dockrell, J.E. (2009). Causes of delay and difficulty in the production of written text. In R. Beard, M. Nystrand, \& J. Riley (Eds.), The Sage handbook of writing development (pp. 489-505). London: Sage Publications Limited.

Dockrell, J.E., \& Connelly, V. (2009). The impact of oral language skills on the production of written text. British Journal of Educational Psychology (monograph), 6, $45^{-62 .}$

Dockrell, J.E., \& Connelly, V. (2015). The role of oral language in underpinning the text generation difficulties in children with specific language impairment. Journal of Reading Research, 38(1), 18-34. doi:10.1111/j.1467-9817.2012.01550.x

Dockrell, J.E., \& Connelly, V. (2016). The relationships between oral and written sentence generation in English speaking children: The role of language and literacy skills. In J. Perrara, M. Aparici, E. Rosado, \& N. Salas. (Eds.), Written and spoken language development across the lifespan. (pp. 161-177) New York:Springer International Publishing.

Dockrell, J.E., Lindsay, G., \& Connelly, V. (2009). The impact of specific language impairment on adolescents' written text. Exceptional Children, 75(4), 427-446.

Dockrell, J.E., Lindsay, G., Connelly, V., \& Mackie, C. (2007). Constraints in the production of written text in children with SLI. Exceptional Children, 73, 147-164.

Dunning, D.L., Holmes, J., \& Gathercole, S.E. (2013). Does working memory training lead to generalized improvements in children with low working memory? A randomized controlled trial. Developmental Science, 16(6), 915-925.

Fayol, M. (1999). Writing: From on-line management problems to strategies. In M. Torrance \& G. Jeffery (Eds.), Cognitive demands of writing (pp.13-23). Amsterdam: Amsterdam University Press.

Flower, L., \& Hayes, J.R. (1980). The dynamics of composing: Making plans and juggling constraints. In L.W. Gregg \& E.R. Steinberg (Eds.), Cognitive processes in writing (pp. 31-5o). Hillsdale, NJ: Erlbaum.

Galbraith, D., Ford, S., Walker, G., \& Ford, J. (2005). The contribution of different components of working memory to knowledge transformation during writing. $\mathrm{LI}^{-}$ Educational Studies in Language and Literature, 5(2), 113-145.

Gillespie, A., \& Graham, S. (2014). A meta-analysis of writing interventions for students with learning disabilities. Exceptional Children, 8o(4), 454-473.

Gillespie, A., Graham, S., Kiuhara, S., \& Hebert, M. (2014). High school teachers' use of writing to support students' learning. Reading and Writing, 27, 1043-1072.

Grabowski, J. (2008). The internal structure of university students' keyboard skills. Journal of writing research, 1(1), 27-52.

Graham, S., \& Hebert, M. (2010) Writing to read: Evidence on how writing can improve reading. Washington D.C.: Carnegie Trust. 
Graham, S., \& Perin, D. (2007). A meta-analysis of writing instruction for adolescent students. Journal of Educational Psychology, 99(3). 445-476.

Graham, S., Harris, K.R., Bartlett, B.J., Popadopoulou, E., \& Santoro, J. (2016). Acceptability of adaptations for struggling writers: A national survey with primary-grade teachers. Learning Disability Quarterly, 39(1), 5-16. DoI: 10.1177/o731948714554038.

Graham, S., Capizzi, A., Harris, K.R., Hebert, M., \& Morphy, P. (2014). Teaching writing to middle school students: A national survey. Reading and Writing, 27(6), 10151042.

Hayes, J.R. (2011). Kinds of knowledge telling: Modelling early writing development. Journal of Writing Research, 3, 73-92.

Hayes, J.R., \& Berninger, V. (2014). Cognitive process in writing: A Framework. In B. Arfé, J.E. Dockrell, \& V.W. Berninger (Eds.), Writing development in children with hearing loss, dyslexia or oral language problems: Implications for assessment and instruction (pp. 3-15). New York: Oxford University Press.

Hayes, J.R., \& Olinghouse, N.G. (2015). Can cognitive writing models inform the design of the Common Core State Standards? The Elementary School Journal, 115(4), 480497.

Johansson, R., Wengelin, Å., Johansson, V., \& Holmqvist, K. (2010). Looking at the keyboard or the monitor: Relationship with text production processes. Reading and Writing, 23(7), 835-851.

Juzwik, M.M., Curcic, S., Wolbers, K., Moxley, K.D., Dimling, L.M., \& Shankland, R.K. (2006). Writing into the 21st century an overview of research on writing, 1999 to 2004. Written Communication, 23(4), 451-476.

Kandel, S., Hérault, L., Grosjacques, G., Lambert, E., \& Fayol, M. (2009). Orthographic vs. phonologic syllables in handwriting production. Cognition, 110(3), 440-444.

Kellogg, R.T., Olive, T., \& Piolat, A. (2007). Verbal, visual, and spatial working memory in written language production. Acta Psychologica, 124(3), 382-397.

Kellogg, R.T., Whiteford, A.P., Turner, C.E., Cahill, M., \& Merlens, A. (2013). Working memory in written composition: An evaluation of the 1996 model. Journal of Writing Research, 5(2). 22-38.

MacArthur, C. (2006). Assistive technology for writing: Tools for struggling writers. In L. Van Waes, M. Leijten, \& C. Neuwirth (Vol. Eds.) \& G. Rijlaarsdam (Series Ed.), Studies in writing, Vol. 17. Writing and digital media (pp. 11-20). Oxford: Elsevier.

MacArthur, C., \& Graham, S. (2016). Writing research from a cognitive perspective. In C. MacArthur, S. Graham, \& J. Fitzgerald (Eds) Handbook of writing research, 2nd Edition (pp. 24-40). New York: Guilford Publications.

McCutchen, D. (2011). From novice to expert: Implications of language skills and writing-relevant knowledge for memory during the development of writing skill. Journal of Writing Research, 3(1), 51-68. 
McCutchen, D., Stull, S., Herrera, B.L., Lotas, S., \& Evans, S. (2014). Putting words to work: Effects of morphological instruction on children's writing. Journal of Learning Disabilities, 47(1), 86-97.

Mehta, P.D., Foorman, B.R., Branum-Martin, L., \& Taylor, W.P. (2005). Literacy as a unidimensional multilevel construct:Validation, sources of influence, and implications in a longitudinal study. Scientific Studies of Reading, 9(2), 85-116.

Morphy, P., \& Graham, S. (2012). Word processing programs and weaker writers/readers: A meta-analysis of research findings. Reading and Writing, 25, 641-648.

Mortimore, T., \& Crozier, W.R. (2006). Dyslexia and difficulties with study skills in higher education. Studies in Higher Education, 31, 235-251.

Mueller, P.A., \& Oppenheimer, D.M. (2014). The pen is mightier than the keyboard: Advantages of longhand over laptop note taking. Psychological Science, 25, 1159-1168.

Olive, T. (2014). Toward a parallel and cascading model of the writing system: A review of research on writing processes. Journal of Writing Research, 6(2), 173-19o.

Olive, T., \& Kellogg, R.T. (2002). Concurrent activation of high-and low-level production processes in written composition. Memory \& Cognition, 30(4), 594-6oo.

Olive, T., Kellogg, R.T., \& Piolat, A. (2008). Verbal, visual, and spatial working memory demands during text composition. Applied Psycholinguistics, 29(04), 669-687.

Pontart, V., Bidet-Ildei, C., Lambert, E., Morisset, P., Flouret, L., \& Alamargot, D. (2013). Influence of handwriting skills during spelling in the primary and lower secondary grades. Frontiers in Psychology. Cognitive Science. Doi 10.3389/fpsyg.2013.00818.

Puranik, C.S., \& Lonigan, C.J. (2012). Early writing deficits in preschoolers with oral language difficulties. Journal of Learning Disabilities, 45(2), 179-19o.

Puranik, C.S., Lombardino, L.J., \& Altmann, L.J. (2007). Writing through retellings: An exploratory study of language-impaired and dyslexic populations. Reading and Writing, 20(3), 251-272.

Prunty, M.M., Barnett, A.L., Wilmut, K., \& Plumb, M.S. (2014). An examination of writing pauses in the handwriting of children with Developmental Coordination Disorder. Research in Developmental Disabilities, 35(11), 2894-2905.

Richards, T.L., Berninger, V.W., \& Fayol, M. (2009). fMRI activation differences between 11-year-old good and poor spellers' access in working memory to temporary and long-term orthographic representations. Journal of Neurolinguistics, 22(4), 327-353.

Rønneberg, V., Johansson, C., Mossige, M., Torrance, M., \& Uppstad, P. (this Volume). Why bother with writers? Towards "good enough" technologies for supporting dyslexics. In B. Miller, P. McCardle, \& V. Connelly (Eds.), Writing development in struggling learners: Understanding the needs of writers across the lifecourse. Leiden, The Netherlands: Brill Publishers.

Roux, S., \& Bonin, P. (2012). Cascaded processing in written naming: Evidence from the picture interference paradigm. Language and Cognitive Processes, 27, 734-769.

Shanahan, T. (2006). Relations among oral language, reading and writing development. 
In C. MacArthur, S. Graham, \& J. Fitzgerald (Eds.), Handbook of writing research (pp. 171-183). New York: Guilford Press.

Shanahan, T. (2015). Relationships between reading and writing development. In C. MacArthur, S. Graham, \& J. Fitzgerald (Eds.) Handbook of writing research, 2nd Edition (pp. 194-210). New York: Guilford Publications.

Sumner, E., Connelly, V., \& Barnett, A.L. (2014a). The influence of spelling ability on handwriting production: Children with and without dyslexia. Journal of Experimental Psychology: Learning, Memory, and Cognition, 4O(5), 1441-1447.

Sumner, E., Connelly, V., \& Barnett, A.L. (2016). The influence of spelling ability on vocabulary choices when writing for children with dyslexia. Journal of Learning Disabilities, 49(3), 293-304. doi:10.1177/oo22219414552018

Sumner, E., Connelly, V., \& Barnett, A.L. (2013). Children with dyslexia are slow writers because they pause more often and not because they are slow at handwriting execution. Reading \& Writing: An Interdisciplinary Journal, 26 (6), 991-10o8.

Sumner, E., Connelly, V., and Barnett, A.L. (In press) Examining the writing process and product of university students with and without dyslexia. Journal of Learning Disabilities.

Swanson, H.L., \& Berninger, V.W. (1996a). Individual differences in children's working memory and writing skill. Journal of Experimental Child Psychology, 63(2), 358-385.

Swanson, H.L., \& Berninger, V.W. (1996b). Individual differences in children's writing: A function of working memory or reading or both processes? Reading and Writing, $8(4), 357-383$.

Torrance, M., \& Galbraith, D. (2006). The processing demands of writing. In C.A. MacArthur, S. Graham, \& J. Fitzgerald (Eds.), Handbook of writing research (pp. 67-80). New York: Guilford.

Van Waes, L., Leijten, M., \& Quinlan, T. (2010) Reading during sentence composing and error correction: A multilevel analysis of the influences of task complexity. Journal of Reading and Writing, 23, 803-834

Wagner, R.K., Puranik, C.S., Foorman, B., Foster, E., Wilson, L.G., Tschinkel, E., \& Kantor, P.T. (2011). Modeling the development of written language. Reading and Writing, 24(2), 203-22O.

Wengelin, A., Leijten, M., \& Van Waes, L. (2010). Studying reading during writing: New perspectives in research. Reading and Writing, 23, 735-742. 